\title{
Conservation Law of Cell Bioelectricity Membrane Area and Ion Inequality Equation Based on Potassium Channel “Origami Windmill" Model
}

\author{
Zuodong Sun ${ }^{*}$ \\ Ya'ou Brain Science Institute of Heilongiiang province, Harbin 150090, China
}

\begin{abstract}
:
At present, there are misunderstandings and even subversive errors in the understanding of cellular bioelectricity phenomena. The theory explaining the mechanism of bioelectricity generation is the ionic theory, and the ionic theory is based on the membrane theory. The membrane theory may be the correct part, and the ionic theory does not give a definite affirmation; the membrane theory may be the wrong part, and ionic theory does not give a clear negative, instead, has been further strengthened in the later period. Whether it is membrane theory or ionic theory, the author has ignored the structure and characteristics of ion channels, and has not found the essence and law of ion exchange inside and outside the cell membrane. Therefore, the GHK equation and the H-H equation based on the ionic theory have congenital deficiencies. Therefore, it is necessary to put forward a new doctrine on this basis and establish a new mathematical model based on the new doctrine to re-explain the mechanism of bioelectricity generation scientifically and rationally.

This paper is based on the principle of $\mathrm{K}^{+}$channel "origami windmill" model, the conservation law of membrane area of cell action potential ion exchange was proposed, and establishes a new mathematical model of cell action potential based on the conservation law of membrane area-ion inequality equation. The expression of conservation law of membrane area: $S_{A}(t)+S_{B}(t)=S_{0}$, the expression of the ion inequality equation: resting potential $\mathrm{N}=\mathrm{N}_{0}+\mathrm{Vt}$; action potential $\mathrm{N}=$ $\mathrm{N}_{0}+170 \mathrm{t}-90 \mathrm{t}^{2}$.

The conservation law of membrane area holds that bioelectrical activity is a process in which different cations replace each other on the inner surface of the cell membrane. $\mathrm{Cl}^{-}$is already surrounded by the cell membrane at the beginning of cell membrane formation, which determines the "positive" and "negative" of the cell action potential; The cations such as $\mathrm{Na}^{+}, \mathrm{K}^{+}$, etc., the amount of mutual replacement on the inner surface of the cell membrane determines the amplitude of the action potential, and the ratio of mutual replacement complies with the principle that the membrane area is equal and the ions are not equal.

The ion inequality equation, cited the kinematics principle, can not only reflect the nature and rule of cation exchange on the inner surface of cell membrane,but also can reasonable avoid cell membrane expansion force and ionic driving force, completed the bioelectricity generation mechanism from the qualitative to the quantitative expression, supports the preexistence of membrane theory, to verify the theory of brain cell activation, the theory of dove-likeparticles and "origami windmill" model, has opened up a scientific and quantitative description cell action potential new ways and means.
\end{abstract}

* Corresponding author: Zuodong Sun (E-mail: sunzuodong@ pai314.com). 
Keywords: $\mathrm{K}^{+}$channel "origami windmill" model; ionic theory; GHK equation; H-H equation; conservation law of membrane area; ion inequality equation

Using the principle of $\mathrm{K}^{+}$channel "origami windmill" model, the whole process of action potential generation of nerve fiber cells and cardiomyocytes was explained reasonably ${ }^{[1,2]}$. The establishment of the $\mathrm{K}^{+}$channel "origami windmill" model ${ }^{[3]}$ has gone through the deduction process of practice-theory-re-practice-re-theory.Since 1994, the author has applied the transcranial electrical and transcranial magnetic electrical stimulation technology to invent a brain function rehabilitation therapeutic $\operatorname{apparatus}^{[4,5]}$ (1995), a depression therapeutic apparatus (2011) ${ }^{[6,7]}$, a Parkinson's disease therapeutic apparatus ${ }^{[8,9]}(2011)$, and Alzheimer's disease therapeutic $\operatorname{apparatus}^{[10,11]}$ (2014) and other encephalopathy rehabilitation treatment equipment are widely used in the clinical practice of cranial nerve diseases, and have achieved significant rehabilitation treatment effects. As the inventor, in order to clarify the treatment mechanism of equipment and the cause of severe cerebral disease,tracing the source, applying the principles of physical biology, from the cellular and molecular level, "the theory of brain cell activation" ${ }^{[12]}$ (2015), "the theory of dove-like particles"[13] (2019), and “ $\mathrm{K}^{+}$channel'origami windmill'Model” ${ }^{[3]}$ (2019) were successively proposed.

The research work during this period naturally involved the mechanism of cellular bioelectrical phenomena. Through combing the basic theoretical research of bioelectricity and classic experimental results, it is found that there are still misunderstandings, even subversive errors, in the current understanding of cellular bioelectricity phenomena. The theory explaining the mechanism of bioelectricity generation is the ionic theory ${ }^{[14]}$, and the ionic theory is based on the membrane theory ${ }^{[15]}$. Membrane theory believes that "biological tissue has its own bioelectricity when there is no stimulation or excitement". This preexistential view may be true, but the ionic theory does not explicitly affirm it; Membrane theory holds that, "when resting, the potential inside the membrane is negative because the $\mathrm{K}^{+}$outflow causes the negative charge to stay inside the cell", and "when a nerve or muscle excites, the selective permeability of the cell membrane temporarily disappears", this point of view may be the wrong, ionic theory does not give a clear negative, instead,it has been further strengthened in the later research work. Whether it is membrane theory or ionic theory, the presenter has ignored the structure and characteristics of ion channels - the inlet and outlet channels are independent and the ion inlet and outlet channels are "same direction sharing", not found the essence of the cell action 
potential and the rules of ion exchange inside and outside the membrane - the membrane area is equal, and the number of ions is not equal.

Therefore, the mathematical model established according to the ionic theory GHK equation and H-H equation ${ }^{[16-18]}$ have congenital defects. GHK equation refers to Nernst equation and tries to establish the relationship between ion concentration gradient and membrane potential. It is believed that $\mathrm{Cl}^{-}$, like $\mathrm{Na}^{+}$and $\mathrm{K}^{+}$, "go in and out together" inside and outside the cell membrane, and its defects are fundamental; $\mathrm{H}-\mathrm{H}$ equation, is only an empirical equation, there is no linear relationship between each data element, not a reliable molecular model, and references to ohm's law, the cell membrane as a series of resistance, battery and capacitor connected into a circuit, eventually because of too many principles and parameters, makes the solution to the problem becomes extremely complex and difficult to understand (Figure 1), which fails to truly reveal and clarify the nature and laws of cell bioelectricity.

\begin{tabular}{|c|c|c|c|}
\hline$I=C_{M} \frac{\mathrm{d} V}{\mathrm{~d} t}+I_{i}$ & $I_{i}=I_{\mathrm{Na}}+I_{\mathrm{K}}+I_{l}$ & $\stackrel{(3)}{\boldsymbol{I}_{\mathrm{Na}}}=\boldsymbol{g}_{\mathrm{Na}}\left(V-V_{\mathrm{Na}}\right)$ & ${ }^{(4)} I_{\mathbf{K}}=g_{\mathrm{K}}\left(V-V_{\mathbf{K}}\right)$ \\
\hline${ }^{(5)} I_{l}=\bar{g}_{l}\left(V-V_{l}\right)$ & $g_{\mathrm{K}}=\bar{g}_{\mathrm{K}} n^{4}$ & $\frac{\mathrm{d} n}{\mathrm{~d} t}=\alpha_{n}(1-n)-\beta_{n} n$ & $\begin{array}{l}(8) \\
n=n_{\infty}-\left(n_{\infty}-n_{0}\right) \exp \left(-t / \tau_{n}\right)\end{array}$ \\
\hline$n_{\infty}=\alpha_{n} /\left(\alpha_{n}+\beta_{n}\right)$ & ${ }^{(10)} \tau_{n}=1 /\left(\alpha_{n}+\beta_{n}\right)$ & \multicolumn{2}{|c|}{${ }^{(11)} g_{\mathrm{K}}=\left\{\left(g_{\mathrm{K} \infty)^{t}}-\left[\left(g_{\mathrm{K} \infty}\right)^{t}-\left(g_{\mathrm{K} 0}\right)^{t}\right] \exp \left(-t / \tau_{n}\right)\right\}^{4}\right.$} \\
\hline \multicolumn{2}{|c|}{$\alpha_{n}=0.01(V+10) /\left[\exp \frac{V+10}{10}-1\right]$} & $\stackrel{(13)}{\beta_{n}}=0 \cdot 125 \exp (V / 80)$ & (14) $g_{\mathrm{Na}}=m^{3} h \bar{g}_{\mathrm{Na}}$ \\
\hline${ }^{(15)} \frac{\mathrm{d} m}{\mathrm{~d} t}=\alpha_{m}(1-m)-\beta_{m} m$ & ${ }^{(16)} \frac{\mathrm{d} h}{\mathrm{~d} t}=\alpha_{h}(1-h)-\beta_{h} h$ & \multicolumn{2}{|c|}{ (17) $\quad m=m_{\infty}-\left(m_{\infty}-m_{0}\right) \exp \left(-t / \tau_{m}\right)$} \\
\hline \multicolumn{2}{|c|}{$h=h_{\infty}-\left(h_{\infty}-h_{0}\right) \exp \left(-t / \tau_{h}\right)$} & \multicolumn{2}{|c|}{$g_{\mathrm{Na}}=g_{\mathrm{Na}}\left[1-\exp \left(-t / \tau_{m}\right)\right]^{3} \exp \left(-t / \tau_{h}\right)$} \\
\hline \multicolumn{2}{|c|}{$\alpha_{m}=0 \cdot 1(V+25) /\left(\exp \frac{V+25}{10}-1\right)$} & ${ }^{(21)} \beta_{m}=4 \exp (V / 18)$ & $m_{\infty}=\alpha_{m} /\left(\alpha_{m}+\beta_{m}\right)$ \\
\hline$\stackrel{(23)}{\alpha_{h}}=0.07 \exp (V / 20)$ & \multicolumn{2}{|c|}{$\beta_{h}=1 /\left(\exp \frac{V+30}{10}+1\right)$} & ${ }^{(25)} h_{\infty}=\alpha_{h} /\left(\alpha_{h}+\beta_{h}\right)$ \\
\hline \multicolumn{2}{|c|}{$\stackrel{(26)}{I=} C_{M} \frac{\mathrm{d} V}{\mathrm{~d} t}+\bar{g}_{\mathrm{K}} n^{4}\left(V-V_{\mathrm{K}}\right)+\bar{g}_{\mathrm{Na}} m^{3} h\left(V-V_{\mathrm{Na}}\right)+\bar{g}_{l}\left(V-V_{l}\right)$} & ${ }^{(27)} i=\frac{1}{r_{1}+r_{2}} \frac{\partial^{2} V}{\partial x^{2}}$ & $\stackrel{(28)}{i=\frac{1}{r_{2}}} \frac{\partial^{2} V}{\partial x^{2}}$ or $I=\frac{a}{2 R_{2}} \frac{\partial^{2} V}{\partial x^{2}}$ \\
\hline \multicolumn{4}{|c|}{$\frac{a}{2 R_{2}} \frac{\partial^{2} V}{\partial x^{2}}=C_{M} \frac{\partial V}{\partial t}+\bar{g}_{\mathrm{K}} n^{4}\left(V-V_{\mathrm{K}}\right)+\bar{g}_{\mathrm{Na}} m^{3} h\left(V-V_{\mathrm{Na}}\right)+\bar{g}_{l}\left(V-V_{l}\right)$} \\
\hline \multicolumn{4}{|c|}{ (30) $\quad \frac{a}{2 R_{2} \theta^{2}} \frac{\mathrm{d}^{2} V}{\mathrm{~d} t^{2}}=C_{M} \frac{\mathrm{d} V}{\mathrm{~d} t}+\bar{g}_{\mathrm{K}} n^{4}\left(V-V_{\mathrm{K}}\right)+\bar{g}_{\mathrm{Na}} m^{3} h\left(V-V_{\mathrm{Na}}\right)+\bar{g}_{l}\left(V-V_{l}\right)$} \\
\hline \multicolumn{3}{|c|}{ (31) $\quad \frac{\mathrm{d}^{2} V}{\mathrm{~d} t^{2}}=K\left\{\frac{\mathrm{d} V}{\mathrm{~d} t}+\frac{1}{C_{M}}\left[\bar{g}_{\mathrm{K}} n^{4}\left(V-V_{E}\right)+\bar{g}_{\mathrm{Na}_{\mathbf{a}}} m^{3} h\left(V-V_{\mathrm{Na}_{\mathbf{a}}}\right)+\bar{g}_{l}\left(V-V_{l}\right)\right]\right\}$} & $\mu^{2}-K \mu-K g_{0} / C_{M}=0$ \\
\hline \multicolumn{3}{|c|}{ (33) $\frac{\mathrm{d} V}{\mathrm{~d} t}=-\frac{\mathrm{l}}{C_{\mathrm{M}}}\left\{\bar{g}_{\mathrm{K}} n^{4}\left(V-V_{\mathrm{K}}\right)+\bar{g}_{\mathrm{Na}} m^{3} h\left(V-V_{\mathrm{Na}_{\mathrm{a}}}\right)+\bar{g}_{l}\left(V-V_{l}\right)\right\}+\frac{z}{K}$} & $\theta=\sqrt{ }\left(K a / 2 R_{2} C_{M}\right)$ \\
\hline \multicolumn{4}{|c|}{$\delta I=C_{M} \frac{\mathrm{d} \delta V}{\mathrm{~d} t}+\bar{g}_{\mathrm{K}} n_{0}^{4} \delta V-4 \bar{g}_{\mathrm{K}} n_{0}^{3} V_{\mathrm{K}} \delta n+\bar{g}_{\mathrm{Na}} m_{0}^{3} h_{0} \delta V-3 \bar{g}_{\mathrm{Na}} m_{0}^{2} h_{0} V_{\mathrm{Na}} \delta m-\bar{g}_{\mathrm{Na}} m_{0}^{3} V_{\mathrm{Na}} \delta h+\bar{g}_{l} \delta V$} \\
\hline \multicolumn{4}{|c|}{ (36) $\frac{\mathrm{d} \delta n}{\mathrm{~d} t}=\frac{\partial \alpha_{n}}{\partial V} \delta V-\left(\alpha_{n}+\beta_{n}\right) \delta n-n_{0} \frac{\partial\left(\alpha_{n}+\beta_{n}\right)}{\partial V} \delta V \quad$ or $\quad\left(p+\alpha_{n}+\beta_{n}\right) \delta n=\left\{\frac{\partial \alpha_{n}}{\partial V}-n_{0} \frac{\partial\left(\alpha_{n}+\beta_{n}\right)}{\partial V}\right\} \delta V$} \\
\hline
\end{tabular}

Figure 1 Hodgkin and Huxley used to derive part of the mathematical formula of $\mathbf{H}-\mathbf{H}$ equation $^{[19]}$ 
If this situation is not corrected in time, not only does it not help answer the basic biological questions of human health and disease from the source, but may also profoundly affect the future research direction of life science. Therefore, it is necessary to put forward a new doctrine on this basis and establish a new mathematical model based on the new doctrine to re-explain the mechanism of bioelectricity generation scientifically and rationally.

\section{Theoretical basis for creating a new theory}

Using the principle of the $\mathrm{K}+$ channel "origami windmill" model, the entire process of the action potential generation mechanism of nerve fiber cells and cardiomyocytes has been reasonably explained. On this basis, can completely be further proposed a new theory that can reasonably explain the mechanism of bioelectricity generation mechanism, build a new mathematical model.

\section{$1.1 \mathrm{~K}^{+}$channel "origami windmill" model}

The principle of the "origami windmill" model: the repulsive force formed by cations such as $\mathrm{K}^{+}$and positively charged amino acid residues in the channel helix drives the "wind teeth" back and the "windmill" rotate, the speed of the "windmill" determines the "on" and "off" of the $\mathrm{K}^{+}$channel hole relative to $\mathrm{K}^{+}$, its characteristic is that the four channels spiral to form an independent functional unit, which rotates synchronously in one direction, only in no out, and has no dependence on adenosine triphosphate.

Inferred from the "origami windmill" model: there are at least two types of channels on the cell membrane. One type of channel is the Enter (E) channel. The structure is like a $\mathrm{K}^{+}$channel "origami windmill" model. Each cell has at least one $\mathrm{E}$ channel; the other type of channel is Leave (L) channel, whose structure only changes between the "on" and "off" conformations, is a passive one-way flow, and can only in no out, and each cell has more than one $\mathrm{L}$ channel. Both the $\mathrm{E}$ channel and the $\mathrm{L}$ channel have two states of "on" and "off" relative to $\mathrm{K}^{+}$. The pore size when "on" is greater than or equal to the $\mathrm{K}^{+}$diameter, and the pore size when "off" is less than the $\mathrm{K}^{+}$diameter but not less than the $\mathrm{Na}$ diameter. All ion or molecular channels in and out of the cell are "shared in the same direction".

According to the "origami windmill" model, it can be further deduced: the ions that replace each other inside and outside the cell membrane,the inner surface of the cell membrane adheres to the principle that the membrane area is equal and the number of ions is not equal, this is the new theory to be proposed - the core and foundation of the conservation law of membrane area. 


\subsection{Physical phenomena of cell membrane ion exchange}

What types of physical phenomena may be consistent with or similar to those observed in Hodgkin and Huxley ${ }^{[20]}$ (1939) experiments (Figure 2)? Through comparative analysis, it is not difficult to find that the entire process of the cell's resting potential and action potential coincides with the law of the displacement and time of the object's movement, that is: the resting potential is equivalent to a linear movement of the ion at a uniform speed; Action potential rising phase, which is equivalent to the uniform deceleration linear motion of the ion; the action potential falling phase, is equivalent to the ion uniform acceleration linear motion. In particular, the rising phase and falling phase of action potential are more in line with the law of motion of vertical throwing objects.

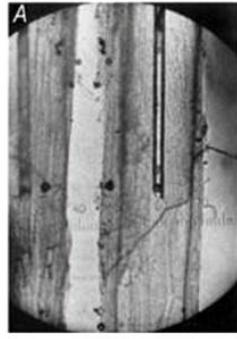

A

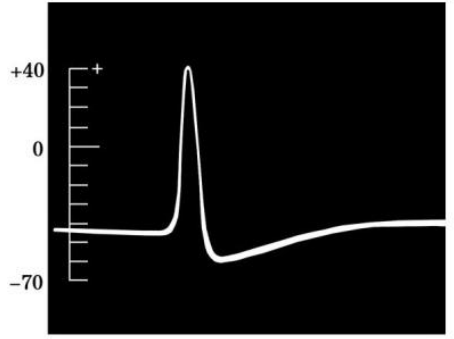

B

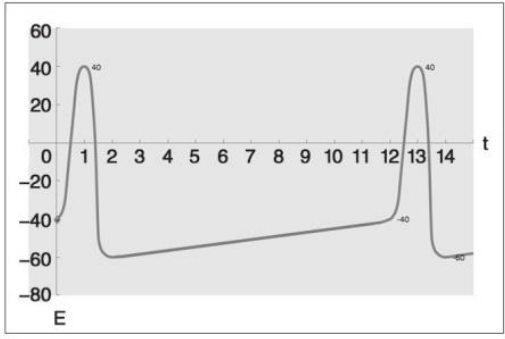

C

Figure 2 Intracellular recording of squid giant axon action potential

Fig. A. Micrograph of the internal electrode of the calamari giant axon (diameter about $500 \mu \mathrm{m}$ ). Two views of the same axon can be seen from the microscope designed by Huxley. Fig. B. The first intracellular action potential record ${ }^{[20]}$. Fig. C. Basic expectation of resting potential and action potential using the inequality equation of ion. Rest potential: $\mathrm{N}=-60+2 \mathrm{t}$, where $\mathrm{t}$ is about $0 \sim 10 \mathrm{~ms}$; action potential: $\mathrm{N}=-40+170 \mathrm{t}-90 \mathrm{t}^{2}$, where $\mathrm{t}$ is about $0 \sim 2 \mathrm{~ms}$.

Therefore, the whole process of cell resting potential and action potential can theoretically be described as follows:

The resting potential, which rises from $-60 \mathrm{mV}$ to $-40 \mathrm{mV}$, is a process where extracellular $\mathrm{Na}^{+}$spins into the cell from the $\mathrm{E}$ channel at a uniform speed. Action potential, relative to $\mathrm{K}^{+}$, rises from $-40 \mathrm{mV}$ to $+40 \mathrm{mV}$, which is the process of intracellular $\mathrm{K}^{+}$from the $\mathrm{L}$ channel uniform deceleration flowing to the extracellular; The decrease from $+40 \mathrm{mV}$ to $-60 \mathrm{mV}$ is a process of uniform acceleration of extracellular $\mathrm{K}^{+}$from the $\mathrm{E}$ channel into the intracellular. Relative to $\mathrm{Na}^{+}$, the increase from $-40 \mathrm{mV}$ to $+40 \mathrm{mV}$ is a process of uniform acceleration of extracellular $\mathrm{Na}^{+}$from the $\mathrm{E}$ channel into the intracellular; the decrease from $+40 \mathrm{mV}$ to $-60 \mathrm{mV}$, is a process of uniform deceleration of intracellular $\mathrm{Na}^{+}$from the $\mathrm{L}$ channel to the extracellular.At $+40 \mathrm{mV}$, the ions on the inner surface of the cell membrane are saturated and all are 
$\mathrm{Na}^{+}$; at $-60 \mathrm{mV}$, the ions on the inner surface of the cell membrane are saturated and all are $\mathrm{K}^{+}$.

\subsection{Relationship between voltage and ion change}

Kinematics is a branch of theoretical mechanics. It describes and studies the changing law of the position of an object with time from a geometric point of view, and does not involve the physical properties of the object itself and the force applied to the object. Therefore, when we use kinematics to establish a mathematical model, we can disregard the expansion force of the cell membrane and the driving force of the ion, as long as the transformation relationship between voltage, charge, ion, and ion number is clarified, and finally the relationship between voltage and time (E-t) is converted to The relationship between ion change and time $(\mathrm{N}-\mathrm{t})$ is sufficient. Of course, the value of membrane voltage, ion current, channel resistance or conductance can also be calculated according to Ohm's law. This article only converts (E-t) to (N-t) or $(\mathrm{N}-\mathrm{t})$ to $(\mathrm{E}-\mathrm{t})$.

For the cell membrane, a small change in charge can produce a large transmembrane potential difference, and the amount of change in ions will only cause a change in the concentration of ions in the cells of 1/10 million. A membrane voltage of $100 \mathrm{mV}$ is generated, and the amount of charge change $\mathrm{Q}$ is equal to the product of $\mathrm{C}_{\mathrm{M}}\left(1 \mu \mathrm{F} / \mathrm{cm}^{2}\right)$ and $\mathrm{E}(0.1$ volt $)$, that is, $\mathrm{Q}=0.1$ microcoulomb $/ \mathrm{cm}^{2}$. Taking monovalent ions as an example, the ion change is: $\mathrm{N}=\mathrm{Q} / \mathrm{e}=0.1 \times 10^{-6}$ (Coulomb / $\left.\mathrm{cm}^{2}\right) / 1.6 \times 10^{-19}($ Coulomb/ion $)=6.25 \times 10^{11}\left(\right.$ ions $\left./ \mathrm{cm}^{2}\right)=6.25 \times 10^{3}\left(\mathrm{ions} / \mu \mathrm{m}^{2}\right)^{[21-23]}$. The average area of the cell membrane is about $2000 \mu \mathrm{m}^{2}$, and the amount of ion change is 1250 ions $/ \mathrm{mV}$. This value will be frequently used in subsequent calculations, so we can set it to a constant $\mathrm{G}$, namely:

$$
G=1.25 \times 10^{3} \text { ions } / \mathrm{mV}
$$

\section{Conservation law of membrane area and mathematical expression}

The conservation law of membrane area is based on the principle of the $\mathrm{K}^{+}$channel "origami windmill" model and the physical phenomenon of ion exchange inside and outside the cell membrane. Its basic content: the bioelectrical activity of cells is the process of different cations inside and outside the cell replacing each other on the inner surface of the cell membrane. The rising phase of action potential is a depolarization process, dominated by $\mathrm{Na}^{+}$influx; the falling phase of action potential of cells is a repolarization process, dominated by $\mathrm{K}^{+}$influx. In the process of cell bioelectricity generation, $\mathrm{Cl}^{-}$is surrounded by the cell membrane at the beginning of the formation of the cell membrane, which determines the "positive" and "negative" of the cell action potential; $\mathrm{Na}^{+}, \mathrm{K}^{+}$and other cations on the inner surface of the cell 
membrane, the amount of mutual replacement determines the amplitude of the action potential. The ratio of the mutual replacement obey the principle that the membrane area is equal and the number of ions is not equal.

The conservation law of membrane area can be written as

$$
S_{\mathrm{A}}(t)+S_{\mathrm{B}}(t)=S_{0}(1)
$$

When the initial moments are all $A$ or $B$, then $S_{A}(0)=S_{0}, S_{B}(0)=0$ or $S_{B}(0)=$ $\mathrm{S}_{0}, \mathrm{~S}_{\mathrm{A}}(0)=0$. It can also be derived from equation (1)

$$
\begin{aligned}
\frac{N_{\mathrm{A}}}{N_{\mathrm{B}}} & =\frac{r_{\mathrm{B}}^{2}}{r_{\mathrm{A}}^{2}} \\
\frac{V_{\mathrm{A}}}{V_{\mathrm{B}}} & =\frac{r_{\mathrm{B}}^{2}}{r_{\mathrm{A}}^{2}} \\
\frac{\mathrm{d} V_{\mathrm{A}}}{\mathrm{d} t} & =-\frac{\mathrm{d} V_{\mathrm{B}}}{\mathrm{d} t}
\end{aligned}
$$

Among them, A and B are the two kinds of ions that replace each other on the inner surface of the cell membrane; $S_{A}$ and $S_{B}$ are the area of the cell membrane occupied by the two ions, $S_{0}$ is the internal surface area of cell membrane; $N_{A}$ and $N_{B}$, the number of $A$ and $B$ ions exchanged; $r_{A}$ and $r_{B}$, radius of $A$ and $B$ ions, unit: $\mu \mathrm{m} ; V_{A}$ and $V_{B}$, ion flow velocity, unit: ions / $m s ; d V_{A} / d t$ and $d V_{B} / d t$, change amount of $A$ and $\mathrm{B}$ ion velocity per unit time, unit : ions $/ \mathrm{ms}^{2}$.

In this paper, the cells are modeled as a sphere, and the formula of sphere surface area was used to calculate the inner surface area of cell membrane $S_{0}=4 \pi R^{2}$. If $A$ and $B$ represent $\mathrm{K}^{+}$and $\mathrm{Na}^{+}$, respectively, according to the previous estimate, $\mathrm{V}_{A} / \mathrm{V}_{\mathrm{B}}$ $=\mathrm{r}_{\mathrm{B}}^{2} / \mathrm{r}_{\mathrm{A}}^{2} \approx 2: 3$. Some scholars calculated the ratio based on the experimental results to be about 37: $63 \approx 2: 3$. However, in order to facilitate understanding, we have used the 2: 3 valuation in subsequent calculations. When the A and B ions are both monovalent, the unit of the number of ions and the unit of charge can be used after simple conversion.

\section{Ion inequality equation and its derivation process}

The entire process of cell resting potential and action potential conforms to the law of kinematics of objects or particles. Based on the conservation law of membrane area, we can try to establish a new mathematical model of cell action potential-ion inequality equation. A complete process of cell bioelectricity generation should include two parts: resting potential and action potential, and action potential includes rising phase and falling phase. 
Kinematics, the four physical quantities that describe the motion of objects and their changes include: position vector, displacement, velocity, acceleration, and its main properties are vector, instantaneous and relative. Understand the meaning and function of the equation of motion, you can master the calculation method of the four physical quantities of the equation of motion.

\subsection{Uniform linear motion and resting potential}

The characteristic of uniform linear motion is speed $V=$ constant. Let the particle move linearly along the $\mathrm{x}$-axis, then by the definition of velocity, we get

$$
\mathrm{V}=\mathrm{d} x / \mathrm{dt} \text { namely } \mathrm{d} x=\mathrm{Vdt}
$$

Let $\mathrm{t}_{0}$ be the particle at $x_{0}$ and the $\mathrm{t}$ be the particle at $x$ then there is:

$$
\int_{x_{0}}^{x} \mathrm{~d} x=\int_{t_{0}}^{t} \mathrm{Vd} t
$$

Because $\quad x-x_{0}=\mathrm{V}\left(\mathrm{t}-\mathrm{t}_{0}\right)$

If $\mathrm{t}_{0}=0$ and $x_{0}=0$, the above formula can be written as $x=\mathrm{Vt}$

This is the well-known equation of uniform linear motion.

The resting potential of the cell corresponds to the uniform linear motion of the object. The change in the number of ions in the equation $\mathrm{N}$ corresponds to $x$ in the equation of uniform linear motion. the change in ions per unit time corresponds to the velocity $\mathrm{V}$ in the equation. If $\mathrm{t}_{0}=0$ and $\mathrm{N}_{0}=\mathrm{N}_{\min }$, then there is:

$$
N=N_{\min }+V t
$$

Among them

$$
\begin{gathered}
N_{\text {min }}=N_{\text {Vth }}-V t \\
N_{\text {Vth }}=N_{\text {max }}-N_{\text {Hei }}=\frac{2}{3} N_{\text {min }}
\end{gathered}
$$

Among them, $\mathrm{N}$ is a physical quantity with size and direction, which is a directed line segment from the initial position to the end position, the direction is from the start point to the end point; $\mathrm{V}$ represents the speed of $\mathrm{Na}^{+}$screwing into the cell from the $\mathrm{E}$ channel, and $t$ is the time of resting potential (About $0 \sim 10 \mathrm{~ms}$ ); $\mathrm{N}_{\min }$ corresponds to the minimum negative value of the action potential falling phase, $\mathrm{N}_{\max }$ corresponds to the maximum positive value of the action potential rising phase, $\mathrm{N}_{\mathrm{Vth}}$ corresponds to the threshold of the triggering action potential; $\mathrm{N}_{\mathrm{Hei}}$ corresponds to the action potential rising phase The maximum amplitude $\left(\mathrm{N}_{\mathrm{Vth}}\right.$ to $\left.\mathrm{N}_{\max }\right)$ is a constant.

If $t_{0}=0$ and $\mathrm{N}_{0} \neq 0$, the quantitative expression of resting potential (5) is a unary one-time function:

$$
N=N_{0}-V t
$$




\subsection{Uniformly variable linear motion and action potential}

The characteristic of uniformly variable linear motion is acceleration $\mathrm{a}=$ constant. Let the particle move in a straight line along the $\mathrm{X}$ axis. From the definition of acceleration, we get

$\mathrm{a}=\mathrm{dV} / \mathrm{dt} \quad \mathrm{dV}=\mathrm{adt}$

If the velocity of the particle at $t=0$ is $\mathrm{V}_{0}$, and the velocity of the particle at $\mathrm{t}$ is $\mathrm{V}$, then there is

$$
\int_{V_{0}}^{V} \mathrm{~d} V=\int_{0}^{t} a \mathrm{~d} t
$$

Namely, $\mathrm{V}-\mathrm{V}_{0}=$ at or $\mathrm{V}=\mathrm{V}_{0}+$ at

And because $\mathrm{V}=\mathrm{dx} / \mathrm{dt}=\mathrm{V}_{0}+\mathrm{at}$

So $\mathrm{dx}=\left(\mathrm{V}_{0}+\mathrm{at}\right) \mathrm{dt}$

If the particle is at position $x_{0}$ at time $\mathrm{t}=0$ and the particle is at position $x$ at time $\mathrm{t}$, then there is

$$
\int_{x_{0}}^{x} \mathrm{~d} x=\int_{0}^{t}\left(V_{0}+a t\right) \mathrm{d} t
$$

Calculus gives $x-x_{0}=V_{0} t+\frac{1}{2} a t^{2}$

If $\mathrm{t}=0, x_{0}=0$ means the particle is at the origin of the coordinate, then there is

$$
x=V_{0} t+\frac{1}{2} a t^{2}
$$

From $V=V_{0}+a t, x=V_{0} t+\frac{1}{2} a t^{2}$, the time parameter $t$ is eliminated,can get

$$
V^{2}-V_{0}^{2}=2 a x
$$

The nature of the motion of the projectile in the vertical direction is a uniformly variable linear motion with an initial velocity of not zero. Set the initial velocity $\mathrm{V}_{0}$ vertically upward as a positive direction, and add the "-" sign before the value of gravity acceleration $\mathrm{g}$. The formula of the motion law of the projectile can be simplified as:

$$
V_{t}=V_{0}-g t, x=V_{0} t-\frac{1}{2} g t^{2}
$$

This method is simple to calculate, but we must pay attention to vectorness and physical quantity symbols. Using this method, several important inferences can also be drawn: the maximum height at which the object can rise $\mathrm{H}_{\mathrm{m}}=\mathrm{V}_{0}{ }^{2} / 2 \mathrm{~g}$; the time required to rise to the maximum height $\mathrm{t}=\mathrm{V}_{0} / \mathrm{g}$; the falling process is the inverse process of the rise process, so the particles are passing through the same at the height position, the rise speed and the fall speed are equal; When the object passes through the same height, the rise time and the fall time are equal. 
The action potential of the cell conforms to the law of the motion of a vertically projected object. The design of the action potential equation is based on the formula of the motion law of a vertically projected object. For the $\mathrm{L}$ channel, set the direction of ion flow from the inside of the cell to the outside of the cell as the "positive direction", then the geometric trajectories of $\mathrm{K}^{+}$and $\mathrm{Na}^{+}$flow with time are in line with the physical situation of vertical object movement, and the change of ion with time $\mathrm{N}$ It is applicable to the formula of the motion law of a projectile thrown vertically, that is, when $\mathrm{t}=0$ and $\mathrm{N}_{0} \neq 0$, then there is:

$$
N=N_{0}+V_{0} t-\frac{1}{2} a t^{2}
$$

Among them, a is acceleration, unit: ions $/ \mathrm{ms}^{2}$; $\mathrm{t}$ is action potential time course, about $0 \sim 2 \mathrm{~ms} ; \mathrm{V}_{0}$ is the initial velocity of $\mathrm{K}^{+}$or $\mathrm{Na}^{+}$escaping from $\mathrm{L}$ channel. When $\mathrm{t}=0, \mathrm{~N}_{0}=\mathrm{N}_{\mathrm{Vth}}$.

Note: The meaning of the letters used in the action potential equation cannot be completely equivalent to the letters in the vertical motion formula of the projectile. For example, $\mathrm{a}$ is acceleration, but it is not equal to the value of $\mathrm{g}$.

According to Figure 2.B, the values of $\mathrm{V}_{0}$ and a can be calculated according to equation (7). Calculation method:

The action potential time $t$ is about $0 \sim 2 \mathrm{~ms}$, the maximum value corresponding to the action potential $\mathrm{N}_{\max }=40 \mathrm{G}$, the minimum value $\mathrm{N}_{\min }=-60 \mathrm{G}$, and the corresponding value of the trigger potential $\mathrm{N}_{0}=\mathrm{N}_{\mathrm{Vth}}=-40 \mathrm{G}$. Assuming that when $\mathrm{t}=1 \mathrm{~ms}$ corresponds to $\mathrm{N}_{\max }=40 \mathrm{G}$, when $\mathrm{t}=2 \mathrm{~ms}$ corresponds to $\mathrm{N}_{\min }=-60 \mathrm{G}$, then there is:

When $\mathrm{t}=1 \mathrm{~ms}, \quad 40=-40+V_{0} t-\frac{1}{2} a t^{2}$

When $\mathrm{t}=2 \mathrm{~ms}, \quad-60=-40+V_{0} t-\frac{1}{2} a t^{2}$

Obtain:

$\mathrm{V}_{0}=170 \mathrm{G}$ (ions $/ \mathrm{ms}$ ), $\mathrm{a}=180 \mathrm{G}$ (ions $/ \mathrm{ms}^{2}$ )

$\mathrm{N}_{\mathrm{Hei}}=\mathrm{H}_{\mathrm{m}}=\mathrm{V}_{0}^{2} / 2 \mathrm{a} \approx 80 \mathrm{G}$

Among them, $\mathrm{V}_{0}$ is the initial velocity of the ion, $\mathrm{a}$ is the acceleration of the ion, and $\mathrm{N}_{\mathrm{Hei}}\left(\mathrm{N}_{\mathrm{Vth}}\right.$ to $\left.\mathrm{N}_{\max }\right)$ is the maximum amplitude of the rising phase. $\mathrm{V}_{0}$, a, $\mathrm{N}_{\mathrm{Hei}}$ can be understood as the universal constant of cell bioelectricity.

The mathematical expression of the action potential is a quadratic function of one variable. Equation (7) can be simplified to:

$$
N=N_{0}+170 t-90 t^{2}
$$




\section{Explanation and verification}

The conservation law of membrane area based on the $\mathrm{K}^{+}$channel "origami windmill" model and the unequal equation of cell action potential ion inequality equation based on the conservation law of membrane area, its scientificity and applicability can be verified by quantitative expression or interpretation of the whole process of action potential occurrence in nerve fiber cells and cardiac muscle cells.

\subsection{Action potentials of nerve fiber cells}

Applying the conservation law of membrane area and the ion inequality equation, explain Figure 2.B. The ratio of the number of $\mathrm{K}^{+}$and $\mathrm{Na}^{+}$replacing each other is $2: 3$. When $2 \mathrm{~K}^{+}$are rotated into from the $\mathrm{E}$ channel, $3 \mathrm{Na}^{+}$will be squeezed out from the $\mathrm{L}$ channel, and there is one more negative charge in the cell, and the proportion is $2: 3: 1$; when $3 \mathrm{Na}^{+}$are rotated into from the $\mathrm{E}$ channel, and $2 \mathrm{~K}^{+}$squeezed out from the $\mathrm{L}$ channel are added, there will be one more positive charge in the cell, and the proportion is $3: 2: 1$.

The rising phase of the action potential, the $\mathrm{K}^{+}$that squeeze out the cell from the $\mathrm{L}$ channel, and the $\mathrm{Na}^{+}$that is rotate into from the $\mathrm{E}$ channel occupy the same area on the inner surface of the cell membrane; The falling phase of the action potential, the $\mathrm{K}^{+}$that rotate into the cell from the $\mathrm{E}$ channel, and the $\mathrm{Na}^{+}$that issqueeze outfrom the $\mathrm{L}$ channel occupies the same area on the inner surface of the cell membrane.

(1) Extreme value of action potential

When $\mathrm{E}_{\max }=+40 \mathrm{mV}$ or $\mathrm{N}_{\max }=+40 \mathrm{G}$, the intracellular membrane surface ions are saturated, all are $\mathrm{Na}^{+}$, the calculation result is $\mathrm{Q}_{\mathrm{Na}}=300 \mathrm{G}$; when $\mathrm{E}_{\min }=-60 \mathrm{mV}$ or $\mathrm{N}_{\min }=-60 \mathrm{G}$, the intracellular membrane surface ions In the saturated state, all are $\mathrm{K}^{+}$, and the calculation result is $\mathrm{Q}_{\mathrm{K}}=200 \mathrm{G}$. Calculation method:

$$
\mathrm{Q}_{\mathrm{Na}}-\mathrm{Q}_{\mathrm{K}}=100 G, \frac{\mathrm{Q}_{\mathrm{K}}}{\mathrm{Q}_{\mathrm{Na}}}=\frac{2}{3}
$$

Among them, $\mathrm{Q}_{\mathrm{Na}}$ represents the amount of $\mathrm{Na}^{+}$on the intracellular membrane, and $\mathrm{Q}_{\mathrm{K}}$ represents the amount of $\mathrm{K}^{+}$on the intracellular membrane.

(2) Action potential rising phase

When the $\mathrm{E}=0 \mathrm{mV}$ or $\mathrm{N}=0$ position, the intracellular membrane surface ions are in a saturated state, and the cell should contain $180 \mathrm{G} \mathrm{Na}^{+}$and $80 \mathrm{G} \mathrm{K}^{+}$, which isequivalent to $180 \mathrm{G} \mathrm{Na}^{+}$rotated into from the $\mathrm{E}$ channel, and $120 \mathrm{G} \mathrm{K}^{+}$squeezed out from the $\mathrm{L}$ channel. Calculation method:

$$
\mathrm{Q}_{\mathrm{NaE}}-\mathrm{Q}_{\mathrm{KL}}=60 G, \frac{\mathrm{Q}_{\mathrm{KL}}}{\mathrm{Q}_{\mathrm{NaE}}}=\frac{2}{3}
$$


Among them, $\mathrm{Q}_{\mathrm{NaE}}$ is the amount of $\mathrm{Na}^{+}$rotated into from the $\mathrm{E}$ channel, and $\mathrm{Q}_{\mathrm{KL}}$ is the amount of $\mathrm{K}^{+}$squeezed out from the $\mathrm{L}$ channel.

(3) Action potential falling phase

When the $\mathrm{E}=0 \mathrm{mV}$ or $\mathrm{N}=0$ position, the intracellular membrane surface ions are in a saturated state, and the cell should contain $180 \mathrm{G} \mathrm{Na}^{+}$and $80 \mathrm{G} \mathrm{K}^{+}$, which is equivalent to $120 \mathrm{G} \mathrm{Na}^{+}$squeezed out from the $\mathrm{L}$ channel and $80 \mathrm{G} \mathrm{K}^{+}$rotated into from the $\mathrm{E}$ channel. Calculation method:

$$
\mathrm{Q}_{\mathrm{NaL}}-\mathrm{Q}_{\mathrm{KE}}=40 G, \frac{\mathrm{Q}_{\mathrm{KE}}}{\mathrm{Q}_{\mathrm{NaL}}}=\frac{2}{3}
$$

Among them, $\mathrm{Q}_{\mathrm{KE}}$ is the amount of $\mathrm{K}^{+}$rotated into from the $\mathrm{E}$ channel, and $\mathrm{Q}_{\mathrm{NaL}}$ is the amount of $\mathrm{Na}^{+}$squeezed out from the $\mathrm{L}$ channel.

By quantitatively expressing the action potential of nerve fiber cells, it can also be inferred that when $\mathrm{E}=0 \mathrm{mV}$ or $\mathrm{N}=0$, the ions on the surface of the intracellular membrane are in a saturated state, and the sum of the amounts of $\mathrm{Na}^{+}$and $\mathrm{K}^{+}$on the intracellular membrane is $260 \mathrm{G}$, the corresponding cell should already have $260 \mathrm{G}$ anion or negative charge. Although the negatively charged cells in addition to $\mathrm{Cl}^{-}$, there may be $\mathrm{HCO}_{3}{ }^{-}, \mathrm{PO}_{4}{ }^{3-}$, proteins, nucleic acids, metabolites with phosphate groups and carboxyl groups ${ }^{[24]}$, but the pre-existing anion of $260 \mathrm{G}$ in the cell is $\mathrm{Cl}^{-}$, It is a high probability event. This inference supports the preexisting view of the membrane theory that biological tissue itself has bioelectricity in the absence of stimulation or excitement.

(4) Action potential threshold

When the position of $E_{\mathrm{Vth}}=-40 \mathrm{mV}$ or $\mathrm{N}_{\mathrm{Vth}}=-40 \mathrm{G}$, which is the trigger potential of the action potential, the ion on the surface of the intracellular membrane is in an excessive saturated state and should contain 200G of $\mathrm{K}^{+}$and $20 \mathrm{G}$ of $\mathrm{Na}^{+}$. Theoretically, when the $\mathrm{E}_{\min }=-60 \mathrm{mV}$ or $\mathrm{N}_{\min }=-60 \mathrm{G}$ position, the $\mathrm{E}$ channel is "off" relative to $\mathrm{K}^{+}$. Therefore, the resting potential period $\mathrm{Vt}=20 \mathrm{G}$, and $\mathrm{t} \approx 10 \mathrm{~ms}, 20 \mathrm{G}$ is $\mathrm{Na}^{+}$rotate into uniformly the cell from the $\mathrm{E}$ channel, and the flow rate of $\mathrm{Na}^{+}$is $\mathrm{V}=2 \mathrm{G}$ (ions/ms). In particular, the flow velocity $\mathrm{V}$ in the resting potential phase is the $\mathrm{Na}^{+}$that rotate into the cell from the E channel at a constant speed, resulting in the "opening" of the $\mathrm{L}$ channel relative to $\mathrm{K}^{+}$. Therefore, $\mathrm{V}$ is not the initial velocity of $\mathrm{Na}^{+}$and $\mathrm{K}^{+}$through the $\mathrm{L}$ channel.

In order to facilitate the understanding of the ion inequality equation, we can change the previous statement about "the action potential rising phase is dominated by $\mathrm{Na}^{+}$inflow and the action potential falling phase is dominated by $\mathrm{K}^{+}$inflow" to "the action potential rising phase is dominated by $\mathrm{K}^{+}$outflow Dominated by the action 
potential falling phase is dominated by $\mathrm{K}^{+}$inflow". In this way, it is easier to explain the meaning of the equation.

\subsection{Action potential of ventricular myocytes}

The theoretical basis of cardiomyocyte action potential is the theory formed by nerve fiber cells. The difference is that in addition to $\mathrm{K}^{+}, \mathrm{Cl}^{-}, \mathrm{Na}^{+}$, there are more $\mathrm{Ca}^{2+}$ participation in the process of cardiomyocyte action potential generation: rising phase $\mathrm{Ca}^{2+}$ influx will shorten Polarization duration; $\mathrm{Ca}^{2+}$ influx in the falling phase will prolong the repolarization duration. Cardiomyocytes include ventricular myocytes, Pu's cells, atrial myocytes, atrioventricular node cells, sinus node cells, etc. Among them, the action potential of ventricular myocytes is the most complex and typical ${ }^{[25,26]}$ (Figure 3).

$\mathrm{K}^{+}, \mathrm{Ca}^{2+}$ space replacement proportion: rotate into $2 \mathrm{~K}^{+}$, squeeze out $3 \mathrm{Ca}^{2+}$, and 4 more negative charges in the cell, and the proportion is 2: 3: 4; Conversely, rotate into $3 \mathrm{Ca}^{2+}$, squeeze out $2 \mathrm{~K}^{+}$, and 4 more positive charges in the cell, and the proportion is 3: $2: 4$.

$\mathrm{Na}^{+}, \mathrm{Ca}^{2+}$ space replacement proportion: rotate into $1 \mathrm{Na}^{+}$, squeeze out $1 \mathrm{Ca}^{2+}$, and 1 more negative charges in the cell,and the proportion is 1: 1: 1; Conversely, rotate into $1 \mathrm{Ca}^{2+}$, squeeze out $1 \mathrm{Na}^{+}$, and 1 more positive charges in the cell, and the proportion is $1: 1: 1$.
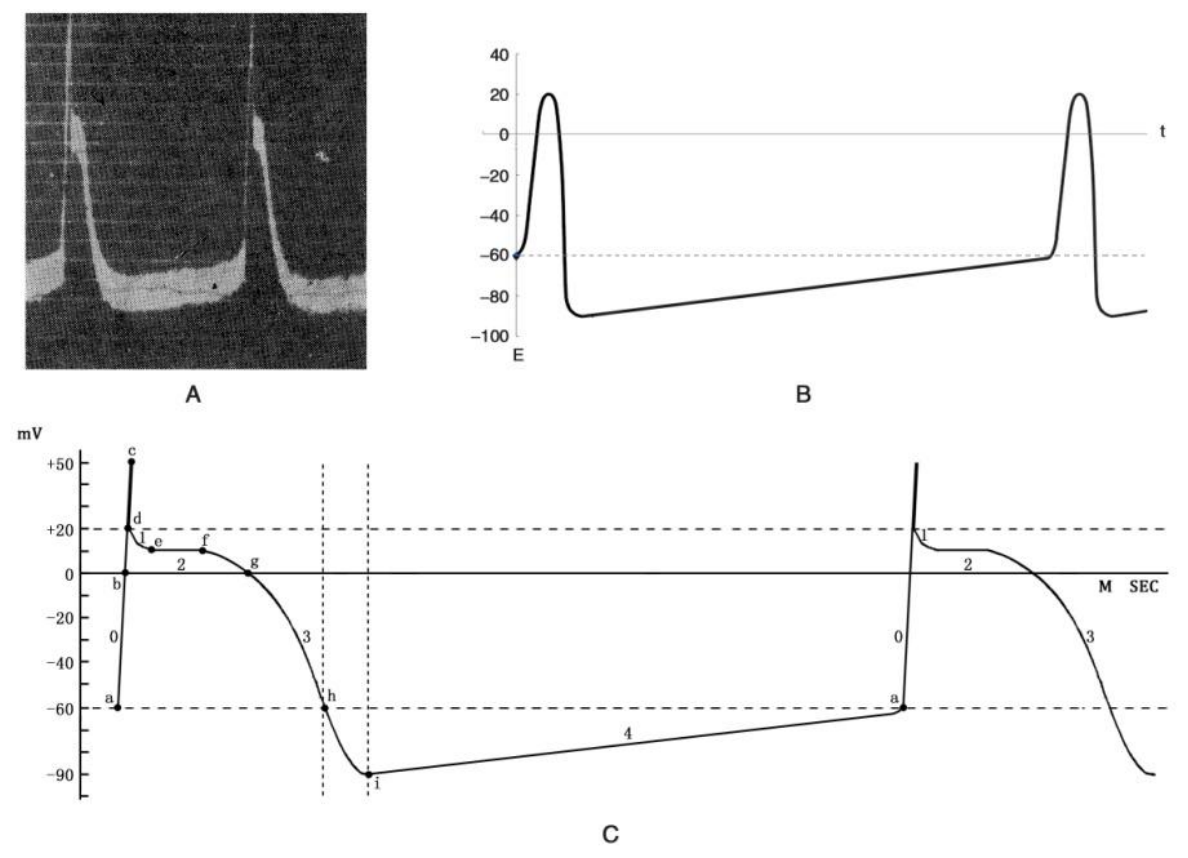

Figure 3 Dog "pseudo-tendon" self-generating activity

Fig. A. Spontaneous activity of a dog "pseudo-tendon" recorded with a hanging wire ammeter. One end of the pseudo-tendon was clipped with tweezers and unidirectional electrical activity was recorded ${ }^{[27,28]}$. Fig. B. Assuming that there is no $\mathrm{Ca}^{2+}$ participation, the basic expectation of graph A using ion inequality equation. Fig. C. Conversion diagram explaining Fig. A. 
$\mathrm{Na}^{+}$diameter (204pm) and $\mathrm{Ca}^{2+}$ diameter (200pm) are almost equal, and the proportion of replace each other with $\mathrm{K}^{+}$(diameter $276 \mathrm{pm}$ ) is the same. However, the diameter of $\mathrm{Na}^{+}$is slightly larger than the diameter of $\mathrm{Ca}^{2+}$. This slight difference has a great influence on the action potential of cardiomyocytes, which determines that $\mathrm{Ca}^{2+}$ will flow out of cells before $\mathrm{Na}^{+}$.

Without considering the participation of $\mathrm{Ca}^{2+}$, equation (8) can be simplified to

$$
N=-60+170 t-90 t^{2}(9)
$$

When $E_{\max }=+20 \mathrm{mV}$ or $\mathrm{N}_{\max }=+20 \mathrm{G}$, the intracellular membrane surface is saturated state, all are $\mathrm{Na}^{+}, \mathrm{Q}_{\mathrm{Na}}=330 \mathrm{G}$; when $\mathrm{E}_{\min }=-90 \mathrm{mV}$ or $\mathrm{N}_{\min }=-90 \mathrm{G}$, the intracellular membrane surface is saturated state, all are $\mathrm{K}^{+}, \mathrm{Q}_{\mathrm{K}}=220 \mathrm{G}$. Calculation method:

$$
Q_{N a}-Q_{K}=110 G, \frac{Q_{K}}{Q_{N a}}=\frac{2}{3}
$$

When the rising phase $\mathrm{E}=0 \mathrm{mV}$ or $\mathrm{N}=0$, the ions on the surface of the intracellular membrane are in a saturated state. The $\mathrm{Na}^{+}$on the intracellular membrane is at least $240 \mathrm{G}$, the $\mathrm{Ca}^{2+}$ is not more than $15 \mathrm{G}$, and the $\mathrm{K}^{+}$is $40 \mathrm{G}$.the intracellular congenital stored of $310 \mathrm{G}$ of $\mathrm{Cl}^{-}$. Calculation method:

$$
\left(Q_{N a E}+2 Q_{C a E}\right)-Q_{K L}=90 G, \frac{Q_{K L}}{Q_{N a E}+2 Q_{C a E}}=\frac{2}{3}
$$

Among them, $\mathrm{Q}_{\mathrm{KL}}$ is $\mathrm{K}^{+}$squeeze out from the $\mathrm{L}$ channel; $\mathrm{Q}_{\mathrm{NaE}}+2 \mathrm{Q}_{\mathrm{CaE}}$ is the number of monovalent ions represented by $\mathrm{Na}^{+}$and $\mathrm{Ca}^{2+}$ rotate into from the $\mathrm{E}$ channel. $\mathrm{Q}_{\mathrm{CaE}}$ calculation method:

$$
Q_{\mathrm{CaE}}=\frac{1}{2}\left(N_{\mathrm{X}}-N_{\max }\right)
$$

Among them, $\mathrm{Q}_{\mathrm{CaE}}$ is the amount of $\mathrm{Ca}^{+}, \mathrm{E}_{\mathrm{X}}=+50 \mathrm{mV}$, the maximum imaginary value of the measured map, equivalent to $\mathrm{N}_{X}=+50 \mathrm{G} ; \mathrm{E}_{\max }=20 \mathrm{mV}$, the actual maximum value of the measured map, equivalent to $\mathrm{N}_{\max }=+20 \mathrm{G} ; \mathrm{N}_{\mathrm{Hei}}=80 \mathrm{G}$ is a constant, so the part that exceeds $\mathrm{N}_{\mathrm{Hei}}$ is caused by $\mathrm{Ca}^{2+}$. $\mathrm{N}_{\mathrm{X}}-\mathrm{N}_{\max }=30 \mathrm{G}$, equivalent to $30 \mathrm{G}$ monovalent cation. The actual situation is the "overshoot" part caused by the participation of divalent $\mathrm{Ca}^{2+}$, which is equivalent to $\mathrm{Q}_{\mathrm{CaE}}=15 \mathrm{G}$. This "overshoot" part should belong to the rising phase of the action potential dominated by $\mathrm{Na}^{+}$.

\subsection{Expectation of action potential}

Through the conservation law of membrane area and the ion inequality equation, can be expectation or restore the action potential diagram of nerve fiber cells (see Figure 2.C, Table 1), equation (8) can be simplified as

$$
N=-40+170 t-90 t^{2}
$$


Through the conservation law of membrane area and the ion inequality equation, can also be expectation or restore the action potential of ventricular myocytes. Without considering the participation of $\mathrm{Ca}^{2+}$, equation (9) can be used as the basic formula for expectating or restoring the action potential diagram of ventricular myocytes, according to which the rest potential and action potential diagrams of ventricular myocytes are prepared (see Figure 3.B, Table 2), And compared with the measured map (Figure 3.C), all the changed parts are the result of $\mathrm{Ca}^{2+}$ participation.

It should be particularly pointed out that whether the measured results of ventricular myocytes or nerve fiber cells are significantly different from the basic expected results of formulas (9) and (10), and the changed part is not the result of $\mathrm{Ca}^{2+}$ participation, which may indicate the cells An exception occurred. For example, "differentiation" caused by excessive participation of unnecessary cations in cells such as $\mathrm{Pb}^{2+}$ and $\mathrm{Cu}^{2+}$. It shows that these cations occupy the position of $\mathrm{K}^{+}$on the inner surface of the cell membrane. This situation should be reflected on the electrocardiogram and electroencephalogram, or it is closely related to heart and brain diseases.

Table 1 Application of ion unequal equation to restore $\mathrm{N}-\mathrm{t}$ data of action potential diagram

\begin{tabular}{ccccccccccc}
\multicolumn{10}{c}{$\mathrm{N}=-40+170 \mathrm{t}-90 \mathrm{t}^{2} \quad(\mathrm{t}$ is about $0 \sim 2 \mathrm{~ms})$} \\
\hline $\mathrm{t}$ & 0 & 0.1 & 0.2 & 0.276 & 0.4 & 0.5 & 0.6 & 0.7 & 0.8 & 0.9 \\
$\mathrm{~N}$ & -40 & -23.90 & -9.60 & 0 & 13.60 & 22.50 & 29.60 & 34.90 & 38.40 & 40.10 \\
\hline $\mathrm{t}$ & 1.0 & 1.1 & 1.2 & 1.3 & 1.4 & 1.5 & 1.613 & 1.7 & 1.8 & 1.89 \\
$\mathrm{~N}$ & 40 & 38.10 & 34.40 & 28.90 & 21.60 & 12.50 & 0 & -11.10 & -25.60 & -40 \\
\hline $\mathrm{t}$ & 1.91 & 1.92 & 1.93 & 1.94 & 1.95 & 1.96 & 1.97 & 1.98 & 1.99 & 2.0 \\
$\mathrm{~N}$ & -43.63 & -45.38 & -47.14 & -48.92 & -50.73 & -52.54 & -54.38 & -56.24 & -58.12 & -60 \\
\hline
\end{tabular}

Table 1 Application of ion unequal equation to restore $\mathrm{N}-\mathrm{t}$ data of action potential diagram

\begin{tabular}{ccccccccccc}
\multicolumn{10}{c}{$\mathrm{N}=-60+170 \mathrm{t}-90 \mathrm{t}^{2} \quad(\mathrm{t}$ is about $0 \sim 2 \mathrm{~ms})$} \\
\hline $\mathrm{t}$ & 0 & 0.1 & 0.2 & 0.3 & 0.469 & 0.5 & 0.6 & 0.7 & 0.8 & 0.9 \\
$\mathrm{~N}$ & -60 & -43.90 & -29.60 & -17.10 & 0 & 2.50 & 9.60 & 14.90 & 18.40 & 20.10 \\
\hline $\mathrm{t}$ & 1.0 & 1.1 & 1.2 & 1.3 & 1.419 & 1.5 & 1.6 & 1.7 & 1.8 & 1.89 \\
$\mathrm{~N}$ & 20 & 18.10 & 14.40 & 8.90 & 0 & -7.50 & -18.40 & -31.10 & -45.60 & -60 \\
\hline $\mathrm{t}$ & 1.91 & 1.93 & 1.95 & 1.97 & 1.99 & 2.01 & 2.02 & 2.03 & 2.04 & 2.05 \\
$\mathrm{~N}$ & -63.63 & -67.14 & -70.73 & -74.38 & -78.11 & -81.91 & -83.84 & -85.78 & -87.74 & -90 \\
\hline
\end{tabular}

\subsection{Action potentials of other shapes}

According to the conservation law of membrane area and the ion inequality equation, the action potentials of other different shapes can also be interpreted reasonably (Figure 4). In Figure 4, (1) is the upward "peak value" before the action potential occurs, which is caused by the "excessive" $\mathrm{Na}^{+}$rotate into from the $\mathrm{E}$ channel and squeeze out from 

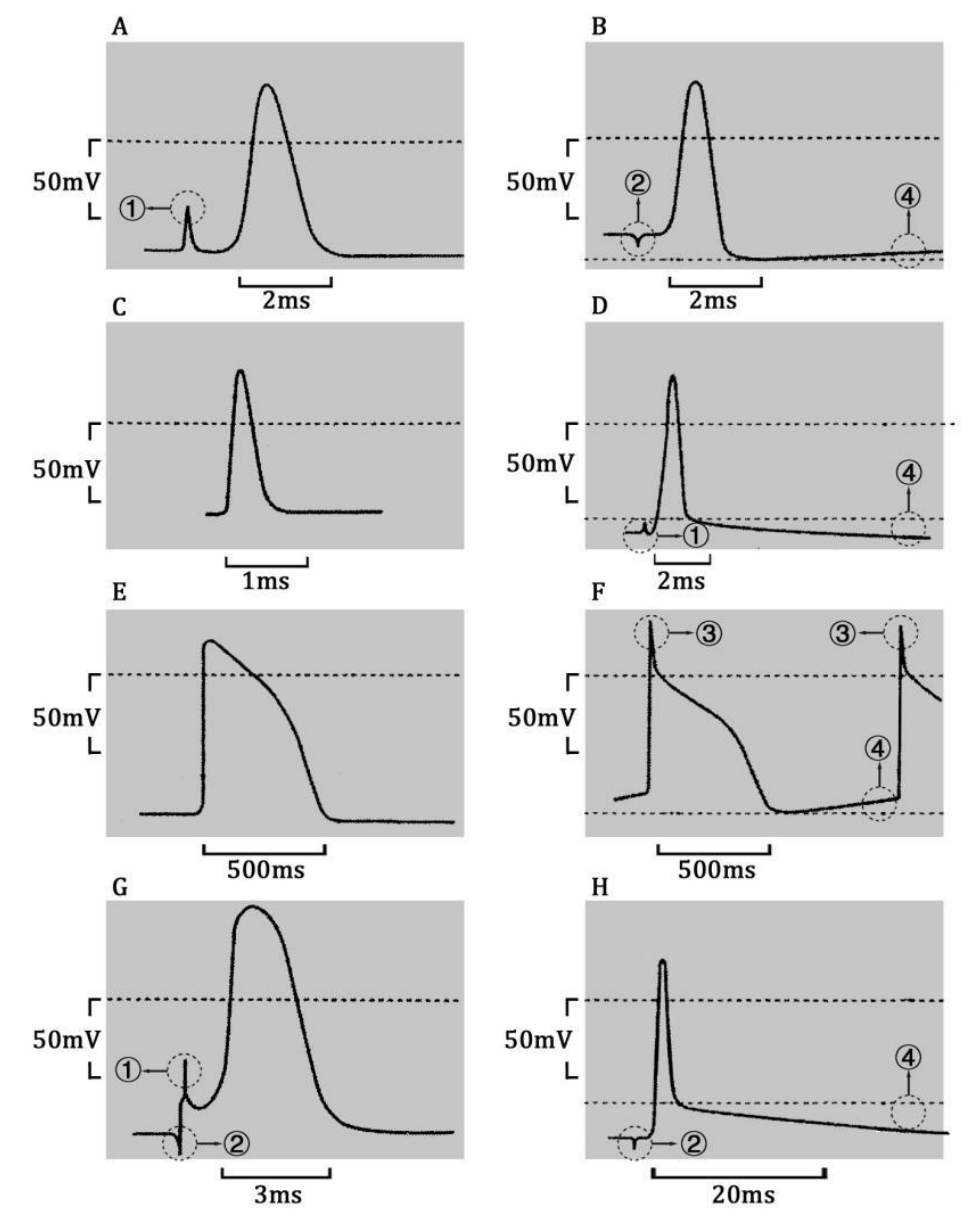

Figure 4 Various shapes of action potential

Action potential curves recorded on different cell types of different animals. The horizontal black dotted line represents zero potential. The top two images compare the action potentials recorded in the giant axon of squid after being dissected from living body $\mathbf{A}$ and $\mathbf{B}$. $\mathbf{C}$ comes from the action potential measured in the cell axons of the cat's peripheral nervous system. D A similar potential measured in the cat's spinal neuron cell body. $\mathbf{E}$ is the action potential recorded in the muscle fiber of the frog's heart rather than in the neuron. $\mathbf{F}$ action potentials recorded by regulatory neurons in the heart of sheep. $\mathbf{G}$ has a fish that can shock its prey with its charged organ, which is composed of abnormally special muscle tissue, recording the potential generated from this tissue. $\mathbf{H}$ the action potential in the more typical muscle cells of the frog's thigh ${ }^{[29,30]}$.

the L channel; (2) It is the downward "peak value" before the action potential occurs, is a "small amount" of $\mathrm{Ca}^{2+}$ instantaneous squeeze out from the $\mathrm{L}$ channel, again caused by the instantaneous rotate into from the $\mathrm{E}$ channel; (3) It is caused by the $\mathrm{Na}^{+}$rotate into from the $\mathrm{E}$ channel, and the intracellular $\mathrm{Ca}^{2+}$ is "squeeze out" of the cell. This "overlapping" part should be attributed to the rising phase dominated by $\mathrm{Na}^{+}$inflow, and should not be classified as the falling phase dominated by $\mathrm{K}^{+}$inflow. This "overlapping" part is the "imaginary value", which can be understood as the "overshoot" caused by $\mathrm{Ca}^{2+}$ participation .Applying the ion inequality equation, $\mathrm{N}_{\max }$ does not include the "overlap" part, but the amount of $\mathrm{Ca}^{2+}$ involved in the cell ion replacement 
process can be estimated based on the "overlap" part; (4)The reason why the straight line of the resting potential period is inclined downwards with respect to the horizontal axis is that the amount of $\mathrm{Ca}^{2+}$ squeeze out from the $\mathrm{L}$ channel is more than the amount rotating into from the $\mathrm{E}$ channel.

\section{Conclusion}

The conservation law of membrane area based on the $\mathrm{K}^{+}$channel "origami windmill" model is equivalent to a new theory based on the membrane theory; the new mathematical model of cell action potential based on The conservation law of membrane area-ion inequality equation, applied objects kinematics principle can reflect the nature and law of cell bioelectricity, and complete the expression of bioelectricity generation mechanism from qualitative to quantitative, which is essentially different from GHK equation and h-h equation.

The conservation law of membrane area and the ion inequality equation can well explainand restore the experimental results of action potentials of nerve fiber cells and cardiomyocytes; conversely, by explain and restore the experimental results of action potentials of nerve fiber cells and cardiomyocytes, it is verified The scientific and applicability of the conservation law of membrane area and the ion inequality equation are supported, and some views of the membrane theory are supported, the theory of brain cell activation, the theory of dove-like particles and "origami windmill" model are verified, it opens up a new way to describe action potential scientifically and quantitatively.

Finally, it is necessary to explain that since 1994, the author of this article has been engaged in the research of basic theoretical research of brain science and the research and development of encephalopathy rehabilitation equipment, the tasks he has undertaken have been included in the national key new product plan project ${ }^{(1)}$, the national torch plan industrialization project $^{2}$, and the major scientific and technological breakthrough plan project in Heilongjiang ${ }^{(3)}$, he has won the first prize of Heilongjiang Science and Technology Award (invention category) ${ }^{(4)}$ and the first prize of Heilongjiang Excellent New Product ${ }^{(5)}$. He has won many national, provincial and municipal science and technology funds, including Heilongjiang Outstanding Youth Science Fund ${ }^{\circledR}$.The author himself is a technology leader of the leading talent echelon of "biomedical electronics" in Heilongjiang Province ${ }^{(7)}$ the head of Heilongjiang Provincial Brain Disease Rehabilitation Treatment Equipment Engineering Technology Research Center $\left.{ }^{(}\right)$, principal of National Postdoctoral research workstation ${ }^{(9)}$, be selected for the national new century talents project ${ }^{(1)}$, enjoying special allowances of the State Council ${ }^{11}$; Aobo Medical Founder, Dean of 
Ya'ou Brain Science Institute of Heilongjiang province. Founded in 2001, Ya'ou Brain Science Institute of Heilongjiang province is an independent legal entity and a professional academic research institution supported by Harbin Aobo Medical Devices Co., Ltd., focusing on basic theoretical research of brain science.

\section{References:}

[1]Sun ZD. Interpretation of Action Potential Generation Mechanism in Cells by Potassium Channel "Origami Windmill” Model. Journal of US-China Medical Science, 2019, 16(4): 1-7.

[2]Sun ZD. Explain the mechanism of myocardial cell action potential with $\mathrm{K}^{+}$channel "origami windmill" mode. Beijng: National Science and Technology Library[2020-05-22].

https://preprint.nstl.gov.cn/preprint/main.html?action=showFile\&id=8a8b8a986ec502f301723b56 2f3807b5.

[3]Sun ZD. Potassium Channel Origami Windmill Model. Journal of US-China Medical Science, 2019, 16(4): 1-4.

[4]Jiao MD, Sun ZD. Effects of Aobo brain function rehabilitation instrument on cerebral circulation and brain function. Medicine Healthcare Apparatus, 1998, 3: 251-52.

[5]Tian NN. Application of Aobo brain function rehabilitation instrument in post-troke hemiplegia patients. Chinese Journal of Medical Device, 2009, 9: 68.

[6]Harbin Successfully Develops the First Therapeutic Instrument for Depression in the World. Science-Technology\& Publication, 2011, 6: 127.

[7]Zou W, Tang Q, Sun ZD, et al.Clinical Study on Transc-ranial Magnetoelectric Depression Treatment Instrument Treatmenting Depression. viXra.org, viXra:1707.0026, 2017-07-04.

Note: (1)Transcranial magnetoelectric depression insomnia treatment instrument (project number: 2011TJB21022), Ministry of Science and Technology of China, 2011.(2)Transcranial Magnetoelectric Depressive Insomnia Treatment Instrument (Project No. 2012GH040294), Ministry of Science and Technology of China, 2012.(3) Development of tDCS Brain Function Rehabilitation Therapy Apparatus(Project No.: GC13C118), Certificate of Scientific and Technological Achievement Identification: Heikechengjianzi [2016] No. 005. Transcranial magnetoelectric encephalopathy treatment instrument(Parkinson Therapeutic Apparatus) (Project Number: GB09C401), Scientific and Technological Achievement Appraisal Certificate: Heikechengjianzi [2011] No. 27, Development and Application of Transcranial Magnetoelectric Dementia Treatment Instrument (GC12C112), Heike Chengjianzi [2014] No. 34.44Heilongjiang Province Science and Technology Invention First Prize (Certificate Number: 2013030), Heilongiiang Provincial People's Government, 2013.5) Transcranial magnetoelectric depression insomnia treatment instrument (Project No. 2011TJB21022), Heilongjiang Provincial Government, 2011. (6) National innovation fund project acceptance certificate, national innovation fund project approval certificate:Transcranialmagnetoelectric encephalopathy treatment instrument(Project code: 12C26212301482); The Heilongiiang Provincial Outstanding Youth Science Fund was awarded by the Heilongjiang Provincial Natural Science Foundation in 2006.(7)Heilongjiang Provincial Department of Human Resources and Social Security, 2017; "Two butterflies" dancing in the spring of science, Science and Technology Daily, 2013-02-25. 8)Science and Technology Department of Heilongiang Province, 2013. 9Ministry of Human Resources and Social Security, 2013. (10Ministry of Personnel, Ministry of Science and Technology, etc., 2006; Three scholars from our province were selected into the second national "New Century Million Talent Project", Heilongjiang Daily, 2006-12-07; (11) State Council, certificate number: 9230627, 2007. 
[8]Xing XL, Tang Q. Clinical research on influences of transcranial magnetoelectric stimulation on Parkinson's disease.(The assembly of conference papers of the 11th national rehabilitation academic conference of Exercise Therapy Branch of Chinese Association of Rehabilitation

Medicine, 2011).

[9]Tang Q, Zou W, Sun ZD, et al. Clinical study on Transcranial magnetoelectric encephalopathy treatment instrument treatmenting parkinson's disease. Beijng: Sciencepaper Online[2017-02-08]. http://www.paper.edu.cn/releasepaper/content/201702-38.

[10]Tang Q, Zou W, Sun ZD, et al. Clinical study on transcranial magnetoelectric encephalopathy treatment instrument for Alzheimer's disease. Highlights of Sciencepaper Online, 2017, 10(11): 1216-1222.

[11]Successful development of the first therapeutic instrument for Alzheimer disease in the world. Science Technology \& Publication, 2014, 6: 143.

[12]Sun ZD. The Theory of Brain Cell Activation. Journal of US-China Medical Science, 2017, 14(5): 203-211.

[13]Sun ZD. The Theory of Dove-like Particles. Journal of US-China Medical Science, 2019, 16(2): 73-99.

[14]Hodgkin AL, Katz B. The effect of sodium ions on the electrical activity of the giant axon of the squid. J Physiol, 1949, 108: 37-77.

[15]Bernstein J. Untersuchungen zur Thermodynamik der bioelektrischen Ströme. Pflügers Arch, 1902, 92:521-562.

[16]Goldman DE. Potential, impedance, and rectification in membranes. J Gen Physiol, 1943, 27: 37-60.

[17]Hodgkin AL, Huxley AF. Current carried by sodium and potassium ions through the membrane of the giant axon of Loligo. The Journal of Physiology, 1952, 116(4):449-472.

[18]Wang BY. Neuroelectrophysiology. Beijing:People's education Press, 1982.

[19]Hodgkin AL, Huxley AF. A quantitative description of membrane current and its application to conduction and excitation in nerve. The Journal of Physiology, 1952, 117: 500-544.

[20]Hodgkin AL, Huxley AF. Action Potentials Recorded from Inside a Nerve Fibre. Nature, 1939, 144(3651):710-711.

[21]Hodgkin AL, Huxley AF, Katz B. Measurement of current-voltage relations in the membrane of the giant axon of Loligo. J Physiol, 1952, 116: 424-448.

[22]Hille B. Ion Channels of Excitable Membranes. 3th ed. Sunderland MA: Sinauer, 2001.

[23]Han JS. Neuro Science. 3th ed. Beijing: Peking university medical press, 2009.

[24]Alberts B. Zhang XY. Molecular Biology of The Cell. 4th ed. Beijing: Science Press, 2008, 682-724.

[25]Liu TF. Cardiomyocyte electrophysiology. Beijing: Peking University Press, 2000.

[26]Cranefield PF. Action potentials, afterpotentials, and arrhythmias. Circ Res, 1977, 41: 415-423.

[27]Goldenberg M, Rothberger CJ. Arch Ges Physiol, 1936, 238: 137.

[28]Liu TF. Myocardial electrophysiology. Beijing: Peking University Press, 1988.

[29]Keynes RD, Aidley DJ. Nerve and Muscle. England: Cambridge University Press, 2001.

[30]Phillips R, Kondev J, Theriot J. Physical Biology of the Cell. Beijing: Science Press, 2012. 